
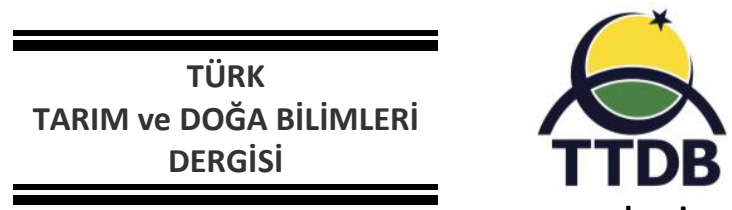

www.dergipark.gov.tr/turkjans

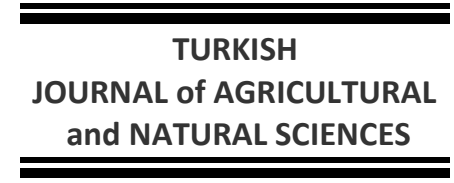

Araştırma Makalesi

\title{
Antalya Doğal Florasında Bulunan Bazı Üçgül (Trifolium sp.) Türlerinin Toplanması ve Morfolojik Karakterizasyonu
}

\author{
Mehmet ÖTEN*, Semiha KiREMitci, Cengiz ERDURMUŞ
}

Batı Akdeniz Tarımsal Araştırma Enstitüsü Müdürlüğü-Antalya

*Sorumlu yazar: moten07@hotmail.com

Geliş Tarihi: 28.09.2018

Düzeltme Geliş Tarihi: 14.02.2019

Kabul Tarihi: 20.02.2019

\begin{abstract}
Özet
Antalya doğal florası yem bitkileri açısından çok zengin genetik varyasyona sahiptir. Yem bitkileri ıslahı konusunda yapılacak öncelikli ve en önemli uygulamalardan birisi yabani formların kültüre alınmalarıdır. Yapılan bu çalışmada; Antalya doğal florasından belirlenen lokasyonlardan 2008-2011 yılları arasında üçgül (Trifolium sp.) türlerine ait 58 populasyon toplanmış ve bu populasyonlardan 2012-2013 yıllarında gözlem bahçesi oluşturularak morfolojik gözlemleri alınmıştır. Lokasyonlardan 10 farklı üçgül türü toplanmış olup, 2 adedinin çok yıllık, 8 adedinin ise tek yıllık olduğu saptanmıştır. Toplanan üçgül türlerine ait 58 populasyonda gözlem yapılmış olup, çiçeklenme gün sayısı 123-190 gün, fizyolojik olum gün sayısı 161-236 gün, bitki boyu 6-70 cm, bin dane ağırlığı 0.4-1.8 g, meyvede tane sayısı 1-5 adet, kömeçte çiçek sayısı 28-82 adet arasında değiştiği belirlenmiştir. Çiçek rengi olarak beyaz, sarı, pembe ve lila renkleri gözlenmiştir. Morfolojik gözlemler dikkate alındığında genetik varyasyonun geniş olduğu söylenebilir. Toplanan genetik materyal, ileri ıslah kademesine aktarılıp, çeşit geliştirme ve kültüre alma amacıyla değerlendirilebilir.
\end{abstract}

Anahtar kelimeler: Üçgül, Trifolium sp., doğal flora, karakterizasyon.

\section{Collecting and Morphological Characterization of Some Clover Species (Trifolium sp.) in Antalya Natural Flora}

\begin{abstract}
Natural flora of Antalya has a very rich genetic variation in terms of forage plants. One of the most important practice to be done on the improvement of forage crops is to take culture of wild forms. In this study, clover seeds were collected in Antalya natural flora between 2008-2011 years. Collected seeds were planted observational garden in land institute for the purpose of the seed multiplication and morphological characteristics were determined during 2012-2013 years. Ten different species of clover were determined in 58 populations, collected from the different locations. Two out of ten clover species were perennial and 8 clover species were annual. It was determinated that number of flowering days ranged 123-190 days, number of physiological maturity ranged 161-236 days, plant height ranged 6-70 cm, thousand seeds weight 04-1.8 g, number seeds of pod ranged 1-5 and the number of flower in head ranged 28-82. Also flower colors observed that as white, yellow, pink and lilac. Considering the morphological observations, it can be said that there is high genotypic variation. Also said that it can be transferred to the advanced breeding stage and evaluated for cultivating and to develop new varieties.
\end{abstract}

Key words: Clover, Trifolium sp., natural flora, characterization.

Giriş

Türkiye florasında yayılış gösteren doğal bitki türleri ve tarımı yapılan kültür formlarının zenginliği ile bitkisel çeşitlilik yönünden büyük bir potansiyele sahiptir. Ancak ülkemizde doğal floradaki bitkilerin ıslahı konusundaki çalışmalar yetersizdir. Doğal floradan toplanan genotiplerden elde edilen çeşitler, yem bitkileri üretimi ve çayır- 
meralarımızın nitelik ve nicelik yönünden geliştirilmesinde, yurt dışından getirilen yabancı materyallere göre daha avantajlı olacaktır. Bu nedenle, öncelikle doğal florada yaygın olarak bulunan yem bitkisi türlerine ait genotiplerin toplanarak, yeni çeşitler geliştirilmesi gerekmektedir.

Türkiye'de yonca, mercimek, fiğ ve korunga türleri ile birlikte üçgül için de mikro gen merkezi konumundadır (Harlan, 1951). Binlerce yıl süren bilinçli veya doğal seleksiyon sonucunda büyük bir genetik çeşitliliğe sahip olan yerel çeşitler, ıslah çalışmaları için çok değerli bir materyal oluşturmaktadır. Özellikle yüksek verimli geliştirilmiş çeşitlerin yaygınlaşması nedeniyle ortadan kaybolma tehlikesi içinde olan yerel çeşitlerin muhafaza edilmesi ve değerlendirilmesi bir zorunluluktur (Ertuş ve ark. 2012).

Bütün dünyada yem bitkisi olarak en çok ilginin çok yıllık türler üzerine yoğunlaşmasına rağmen, yağışın sınırlı, sıcaklığın ise yüksek olduğu bölgelerde tek yıllık yoncalar ve üçgüllerin kendi kendini tohumlamak suretiyle vejatasyonun sürekliliği açısından meralarda daha ümit verici olduğu Carlier ve Machiels (1998), Holt ve Weaver (1981) ile Muir ve ark. (2001) tarafından bildirilmiştir.

Yapılan çalışma ile Antalya doğal florasında bulunan üçgül türleri toplanıp koleksiyon bahçesi oluşturulmuş, 2 yıl süreyle morfolojik gözlemleri alınarak, toplanan üstün özellikli genetik materyalin ileride yapılacak ıslah çalışmalarında değerlendirilmesi amaçlanmıştır.

\section{Materyal ve Yöntem}

Çalışma 2008-2013 yıllarında yürütülmüş olup, 2008-2011 yıllarında üçgül (Trifolium sp.) türleri; Antalya ili doğal florasındaki, çayır meralar, dağlar, vadiler, nehir yatakları, ormanlar gibi doğal alanlar, tarla kenarları ve bahçelerden toplanmıştır. Arazi çalışmaları için lokasyonlar Davis, (1982)'e göre belirlenerek, tohum verme zamanları dikkate alınıp, gidiş tarihleri düzenlenmiştir. Bitkilerin bulundukları yerlerin GPS değerleri belirlenmiş ve Çizelge 1'de verilmiştir.

Tohum toplama işlemi tamamlandıktan sonra iki yıl süre ile tarla denemesi kurulmuştur. Tarla Denemeleri 2012-213 yıllarında Batı Akdeniz Tarımsal Araştırma Enstitüsü Müdürlüğü deneme alanında yürütülerek kültürel işlemler eksiksiz olarak yapılmıştır. Koleksiyon bahçesinde populasyonların her biri $2 \mathrm{~m}$ sıra uzunluğu, $2 \mathrm{~m}$ sıra arası olacak şekilde ikişer sıra halinde ekilip, hem materyalin çoğaltımı sağlanmış, hem de iki yıl süreyle gözlemleri alınmıştır. Çalışmada, çiçeklenme gün sayısı (gün), fizyolojik olum gün sayısı (gün), çiçek rengi, bitki boyu $(\mathrm{cm})$, bin tane ağırlığı (g), meyvede tane sayısı (adet) ve kömeçte çiçek sayısı (adet) gözlemleri Anonim, (2001)'de belirtilen yöntemlere göre alınmıştır. Ayrıca, çiçeklenme döneminde alınan bitki örneklerinden türler teşhis edilmiştir. Türlerin teşhisinde, "Türkiye'nin Çayır ve Mera Bitkileri" kılavuz kitabı Anonim, (2008) ve Davis, (1982)'den faydalanılmıştır.

Çalışmanın yürütüldüğü Antalya ili, Batı Akdeniz sahil kuşağında olup, yazları sıcak ve kurak, kışların ılık ve yağışı bir iklim yapısına sahiptir. Ancak bazı ilçeleri gerek rakımı, gerekse coğrafi konumu dolayısıyla geçit kuşağı iklim özelliklerine sahiptir. Yetiştirme periyodunda ilk yıl yağış miktarı 935 mm, ikinci yıl 784 mm olarak tespit edilmiştir. Uzun yıllar ortalaması ise $931.6 \mathrm{~mm}$ dir. Sıcaklık değeri ise uzun yıllar ortalaması verileri ile benzerlik göstermektedir (Çizelge 1). Toprak özellikleri bakımından tarımsal üretimi kısıtlayıcı herhangi bir durum söz konusu değildir.

Çizelge 1. Antalya İli 2012-2013 ve uzun yıllar iklim verileri

\begin{tabular}{|c|c|c|c|c|c|c|c|c|c|c|c|}
\hline \multirow[b]{2}{*}{ Yıllar } & \multirow[b]{2}{*}{ İklim öğeleri } & \multicolumn{10}{|c|}{ Aylar } \\
\hline & & Ekim & Kasım & Aralık & Ocak & Şubat & Mart & Nisan & Mayıs & Haziran & $\begin{array}{c}\text { Toplam / } \\
\text { Ortalama }\end{array}$ \\
\hline \multirow{2}{*}{ 겅 궁 } & Yağış (mm) & 259 & 20.0 & 125.0 & 234.0 & 122.0 & 56.0 & 41.0 & 74.0 & 4.0 & 935.0 \\
\hline & Ort. Sıcaklık $\left({ }^{\circ} \mathrm{C}\right)$ & 18.6 & 12.4 & 10.4 & 8.9 & 9.2 & 12.5 & 16.7 & 20.5 & 26.0 & 15.02 \\
\hline \multirow{2}{*}{ 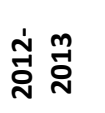 } & Yağış (mm) & 124 & 26.0 & 263.0 & 203.0 & 59.0 & 19.0 & 34.0 & 56.0 & 0.0 & 784.0 \\
\hline & Ort. Sicaklık $\left({ }^{\circ} \mathrm{C}\right)$ & 18.1 & 15.9 & 9.6 & 10.8 & 12.1 & 13.3 & 17.7 & 22.5 & 25.4 & 16.16 \\
\hline \multirow{2}{*}{$\stackrel{\frac{c}{\bar{N}}}{\stackrel{\frac{1}{亠}}{\bar{\Sigma}}}$} & Yağış (mm) & 134.4 & 77.8 & 182.5 & 245.7 & 133.2 & 48.2 & 55.8 & 49.8 & 4.2 & 931.6 \\
\hline & Ort. Sıcaklık ( $\left.{ }^{\circ} \mathrm{C}\right)$ & 20.3 & 15.4 & 11.6 & 10.2 & 11.1 & 13.7 & 16.4 & 21.0 & 25.9 & 16.18 \\
\hline
\end{tabular}




\section{Bulgular ve Tartışma}

Üç yıl süreyle Antalya doğal florasından toplanan toplam 58 populasyondan; Tarla üçgülü (Trifolium arvense L.), Maki üçgülü, (Trifolium boissieri Guss. Ex Boiss), Çilek üçgülü (Trifolium fragiferum L.), Tüylü üçgül (Trifolium hirtum All.), Titrek üçgül (Trifolium physodes Stev.ex Bieb.), Ak üçgül (Trifolium repens L.), Anadolu üçgülü (Trifolium resupinatum L.), Çayır üçgülü (Trifolium pratense L.), Yıldızıı üçgül (Trifolium stellatum L.) ve Pamuklu üçgül (Trifolium tomentosum L.) olmak üzere 10 üçgül türü teşhis edilmiştir. Teşhisi yapılan Trifolium arvense L.'den 3, Trifolium fragiferum L.'den 5, Trifolium hirtum All.'den 7, Trifolium hirtum All.'den 4, Trifolium physodes Stev.ex Bieb.'den 4, Trifolium repens L.'den 8, Trifolium resupinatum L.'den 7 , Trifolium pratense L.'den 5, Trifolium stellatum L.'den 8 ve Trifolium tomentosum L.'den 7 populasyon belirlenmiştir.

Gözlem bahçesindeki türlere ait iki yılın ortalaması maksimum ve minimum gözlem değerleri Çizelge 2'de verilmiştir. Gözlem değerleri incelendiğinde; çiçeklenme gün sayısı türlere göre değişmekte, en düşük değer çilek üçgülünde 123 gün olarak bulunurken, en yüksek değer anadolu üçgülünde 190 gün olarak bulunmuştur. Fizyolojik olum gün sayısı titrek üçgülde 161 gün ile en düşük değer olarak bulunurken, en yüksek değer anadolu üçgülünde 236 gün olarak belirlenmiştir. Çiçek rengi türlere göre değişkenlik göstermiş olup, beyaz, pembe, sarı, lila olarak gözlenmiştir. Bitki boyu türlere göre değişmekte, en düşük değer tarla üçgülünde $6 \mathrm{~cm}$ olarak bulunurken, en yüksek değer çayır üçgülünde $70 \mathrm{~cm}$ olarak bulunmuştur. Bin dane ağırlığı bakımından ise en düşük değer ak üçgül ve pamuklu üçgülde $0.4 \mathrm{~g}$, en yüksek değer ise çayır üçgülünde $1.8 \mathrm{~g}$ olarak belirlenmiştir. Kömeçte çiçek sayısı 28-82 adet arasında, meyvede tane sayısı ise türlere göre 1-5 adet arasında değişmiştir.

Başaran ve ark. (2006), Samsun'da doğal olarak yetişen bazı baklagil yem bitkilerinin bazı morfolojik ve tarımsal özellikleri ile ilgili yaptıkları çalışmada tarla üçgülü, çilek üçgülü, çayır üçgülü, ak üçgül ve anadolu üçgülünde çiçek rengini sırasıyla açık pembe, pembe-beyaz, pembe, kırmızı, beyaz-pembe, bitki boyunu sırasıyla 30-45, 30-55, 70-85, 25-40 ve $20-60 \mathrm{~cm}$ olarak belirlemişlerdir. Daha önce yapılan çalışmalarda Ordu ilinde 16 üçgül türünün doğal florasında bulunduğu belirtilmiş (Deveci ve Şılbır, 2005; Özbucak ve ark. 2006). Yaklaşık 300 üçgül türünden 94 tanesinin anavatanı Anadolu ve Güney-Doğu Avrupa'dır. Karadeniz Bölgesi'nde ise 36 üçgül türünün doğal olarak yetiştiği belirlenmiştir (Manga ve ark. 1995; Acar ve ark. 2001; Mut, 2009; Deveci, 2012; Önal Aşcı ve ark. 2013). Benzer şekilde Antalya florası da üçgül türleri açısından oldukça zengindir.

Üçgül türleri ile ilgili yapılan çalışmalarda; Açıkgöz, (2001) Anadolu üçgülünün 20-60 cm, Namlı ve ark. (1994), Diyarbakır doğal koşullarında Anadolu üçgülü üzerine yaptıkları ekolojik araştırmalarda, bitki boyunun $12.4-73.4 \mathrm{~cm}$, Tekeli ve Ateş (2002), Tekirdağ ekolojik koşullarında, Anadolu üçgülü hatlarında sap uzunluğunun 81.29$94.51 \mathrm{~cm}$, Ertuş, (2005), Van-Edremit ekolojik koşularında Anadolu üçgülünün ortalama bitki boyunun $43.61 \mathrm{~cm}$ olduğunu bildirmişlerdir. Farklı ekolojilerde ve farklı genotiplerle yapılan çalışmalarda, benzer şekilde populasyonlar arasında geniş bir varyasyon olduğu gözlenmiştir. Yapılacak ıslah çalışmaları ile tek yıllık ve çok yıllık üçgül türleri özelliklerine göre değerlendirilerek mera ıslahında ve yeşil ot üretimi açısından değerlendirilebilir.

Çizelge 2. Üçgül populasyonlarının türü, toplandığı yer ve koordinatları

\begin{tabular}{|c|c|c|c|c|c|}
\hline Adı & Türü & Toplandığı yer & \multicolumn{3}{|c|}{ Koordinatlar } \\
\hline ÜÇG 1 & Maki Üçgülü & Nebiler-Yeniköy & $36 \mathrm{~S}$ & 0284735 & UTM 4096555 \\
\hline ÜÇG 2 & Tüylü Üçgül & Gaziler & $36 \mathrm{~S}$ & 0300883 & UTM 4095689 \\
\hline ÜÇG 3 & Çilek Üçgülü & Gaziler mezarlığı & $36 \mathrm{~S}$ & 0302357 & UTM 4097900 \\
\hline ÜÇG 4 & Pamuklu Üçgül & Nebiler & $36 \mathrm{~S}$ & 0284735 & UTM 4096555 \\
\hline ÜÇG 5 & Tarla Üçgülü & Dağbeli mezarlığı & $36 \mathrm{~S}$ & 0277540 & UTM 4119104 \\
\hline ÜÇG 6 & Ak Üçgül & Karaöz-Ekşili & $36 \mathrm{~S}$ & 0301396 & UTM 4114791 \\
\hline ÜÇG 7 & Anadolu Üçgülü & Yağca merası & $36 \mathrm{~S}$ & 0285402 & UTM 4106820 \\
\hline ÜÇG 8 & Yıldızlı Üçgül & Kurşunlu yolu & $36 \mathrm{~S}$ & 0305454 & UTM 4096359 \\
\hline ÜÇG 9 & Titrek Üçgül & Çığlık-Yeniköy & $36 \mathrm{~S}$ & 0282818 & UTM 4102750 \\
\hline ÜÇG 10 & Yıldızlı Üçgül & Çandır & $36 \mathrm{~S}$ & 0325219 & UTM 4088527 \\
\hline ÜÇG 11 & Anadolu Üçgülü & Bermansu deposu & $36 \mathrm{~S}$ & 0331628 & UTM 4090288 \\
\hline ÜÇG 12 & Maki Üçgülü & Zeytintaş magarası yolu & $36 \mathrm{~S}$ & 0331831 & UTM 4091270 \\
\hline ÜÇG 13 & Ak Üçgül & Nebiler & $36 \mathrm{~S}$ & 0283929 & UTM 4095758 \\
\hline ÜÇG 14 & Pamuklu Üçgül & Çandır yolu & $36 \mathrm{~S}$ & 0325219 & UTM 4088527 \\
\hline ÜÇG 15 & Yıldızlı Üçgül & Çığlık & $36 \mathrm{~S}$ & 0283215 & UTM 4101491 \\
\hline
\end{tabular}


Çizelge 2 (Devamı). Üçgül populasyonlarının türü, toplandığı yer ve koordinatları

\begin{tabular}{|c|c|c|c|c|c|}
\hline Adı & Türü & Toplandığı yer & & ordinatlar & \\
\hline ÜÇG 16 & Pamuklu Üçgül & Zeytintaş magarası yolu & $36 \mathrm{~S}$ & 0284735 & UTM 4096555 \\
\hline ÜÇG 17 & Titrek Üçgül & Çandır yolu & $36 \mathrm{~S}$ & 0325424 & UTM 4091391 \\
\hline ÜÇG 18 & Yıldızlı Üçgül & Karaöz-Ekşili & $36 \mathrm{~S}$ & 0305106 & UTM 4111714 \\
\hline ÜÇG 19 & Çilek Üçgülü & Isparta yolu & $36 \mathrm{~S}$ & 0306068 & UTM 4094547 \\
\hline ÜÇG 20 & Tarla Üçgülü & Karaöz-Ekşili yolu & $36 \mathrm{~S}$ & 0301406 & UTM 4114801 \\
\hline ÜÇG 21 & Ak Üçgül & Karaöz-Ekşili yolu (Sömekler) & $36 \mathrm{~S}$ & 0301396 & UTM 4114791 \\
\hline ÜÇG 22 & Tüylü Üçgül & Isparta yolu & $36 \mathrm{~S}$ & 0305529 & UTM 4107502 \\
\hline ÜÇG 23 & Anadolu Üçgülü & Altınova & $36 \mathrm{~S}$ & 0301263 & UTM 4087470 \\
\hline ÜÇG 24 & Çayır Üçgülü & Altınova girişi & $36 \mathrm{~S}$ & 0301336 & UTM 4087477 \\
\hline ÜÇG 25 & Çilek Üçgülü & Altınova & $36 \mathrm{~S}$ & 0300350 & UTM 4092214 \\
\hline ÜÇG 26 & Ak Üçgül & Gaziler mezarlığı & $36 \mathrm{~S}$ & 0302357 & UTM 4097900 \\
\hline ÜÇG 27 & Maki Üçgülü & Selge mezarlık & $36 \mathrm{~S}$ & 0334274 & UTM 4121840 \\
\hline ÜÇG 28 & Anadolu Üçgülü & Gazipaşa kalesi & $36 \mathrm{~S}$ & 0435842 & UTM 4013111 \\
\hline ÜÇG 29 & Çayır Üçgülü & Korkuteli-Fethiye yolu & $36 \mathrm{~S}$ & 0246035 & UTM 4104348 \\
\hline ÜÇG 30 & Yıldızlı Üçgül & Elmalı-Eymir & $35 \mathrm{~S}$ & 0758606 & UTM 4066635 \\
\hline ÜÇG 31 & Ak Üçgül & Ormana-Başlar & $36 \mathrm{~S}$ & 0372113 & UTM 4106349 \\
\hline ÜÇG 32 & Anadolu Üçgülü & Gazipaşa kalesi & $36 \mathrm{~S}$ & 0435842 & UTM 4013111 \\
\hline ÜÇG 33 & Yıldızlı Üçgül & Akçay çıkışı & $35 \mathrm{~S}$ & 0745131 & UTM 4052851 \\
\hline ÜÇG 34 & Pamuklu Üçgül & Akseki & $36 \mathrm{~S}$ & 0390328 & UTM 4105589 \\
\hline ÜÇG 35 & Çilek Üçgülü & Alanya-Güzelbağ & $36 \mathrm{~S}$ & 0402884 & UTM 4065362 \\
\hline ÜÇG 36 & Tüylü Üçgül & Yukarıseki yolu & $36 \mathrm{~S}$ & 0352399 & UTM 4081207 \\
\hline ÜÇG 37 & Anadolu Üçgülü & Elmalı-Kaş arası (Akçay) & $36 \mathrm{~S}$ & 0745131 & UTM 4052851 \\
\hline ÜÇG 38 & Çilek Üçgülü & Evrenseki & $36 \mathrm{~S}$ & 0352327 & UTM 4078586 \\
\hline ÜÇG 39 & Pamuklu Üçgül & Gömbe & $35 \mathrm{~S}$ & 0740168 & UTM 4048850 \\
\hline ÜÇG 40 & Ak Üçgül & Akseki-Beyşehir yolu & $36 \mathrm{~S}$ & 0393296 & UTM 4114095 \\
\hline ÜÇG 41 & Titrek Üçgül & Elmalı-Akçay & $35 \mathrm{~S}$ & 0748032 & UTM 4056240 \\
\hline ÜÇG 42 & Maki Üçgülü & Gündoğmuş yolu & $36 \mathrm{~S}$ & 0399982 & UTM 4074404 \\
\hline ÜÇG 43 & Tüylü Üçgül & Akseki-Sadıklar köyü & $36 \mathrm{~S}$ & 0393216 & UTM 4089072 \\
\hline ÜÇG 44 & Pamuklu Üçgül & Akseki & $36 \mathrm{~S}$ & 0389435 & UTM 4099616 \\
\hline ÜÇG 45 & Tarla Üçgülü & Isparta yolu & $36 \mathrm{~S}$ & 0306372 & UTM 4092880 \\
\hline ÜÇG 46 & Çayır Üçgülü & Finike-Elmalı (Kasaba çıkışı) & $35 \mathrm{~S}$ & 0747799 & UTM 4023347 \\
\hline ÜÇG 47 & Pamuklu Üçgül & Kovanlık & $36 \mathrm{~S}$ & 0287753 & UTM 4114290 \\
\hline ÜÇG 48 & Çilek Üçgülü & Gazipaşa-Helimli & $36 \mathrm{~S}$ & 0438192 & UTM 4011328 \\
\hline ÜÇG 49 & Titrek Üçgül & Taşağıl-Kargıhan & $36 \mathrm{~S}$ & 0355910 & UTM 4096783 \\
\hline ÜÇG 50 & Yıldızlı Üçgül & Gazipaşa kalesi & $36 \mathrm{~S}$ & 0435842 & UTM 4013111 \\
\hline ÜÇG 51 & Ak Üçgül & Selge & $36 \mathrm{~S}$ & 0334274 & UTM 4121846 \\
\hline ÜÇG 52 & Anadolu Üçgülü & Selge & $36 \mathrm{~S}$ & 0334274 & UTM 4121846 \\
\hline ÜÇG 53 & Çayır Üçgülü & Taşağıl-Kargıhan yolu & $36 \mathrm{~S}$ & 0345407 & UTM 4096555 \\
\hline ÜÇG 54 & Yıldızlı Üçgül & Gömbe & $36 \mathrm{~S}$ & 0284735 & UTM 4090592 \\
\hline ÜÇG 55 & Çayır Üçgülü & Taşağıl & $36 \mathrm{~S}$ & 0343093 & UTM 4089964 \\
\hline ÜÇG 56 & Ak Üçgül & Taşağıl-2 & $36 \mathrm{~S}$ & 0343093 & UTM 4089964 \\
\hline ÜÇG 57 & Maki Üçgülü & İbradı & $36 \mathrm{~S}$ & 0380367 & UTM 4104317 \\
\hline ÜÇG 58 & Çilek Üçgülü & Ibradı-2 & $36 \mathrm{~S}$ & 0380367 & UTM 4104317 \\
\hline
\end{tabular}




\section{Sonuç ve Öneriler}

Sonuç olarak; Antalya florasının üçgül türleri yönünden zengin potansiyele sahip olduğu belirlenmiştir. Morfolojik gözlemler neticesinde genetik varyasyonun geniş olduğu, yapılacak ıslah çalışmalarında kullanılabilecek kaliteli ot verimi sağlayacak genotiplerin yanında mera tipi yatık ve yarı yatık populayonlarının olduğu da gözlemlenmiştir.

Çizelge 3. Üçgül (Trifolium sp) türlerine ait gözlemler

\begin{tabular}{|c|c|c|c|c|c|c|c|c|c|c|}
\hline $\begin{array}{l}\text { Alınan } \\
\text { gözlemler }\end{array}$ & 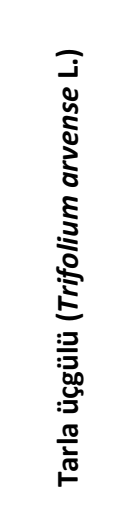 & 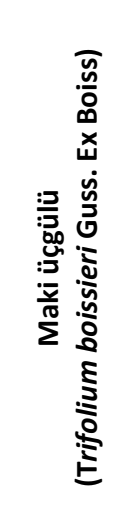 & 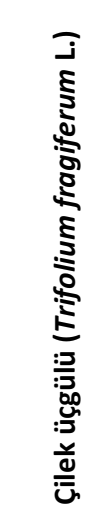 & 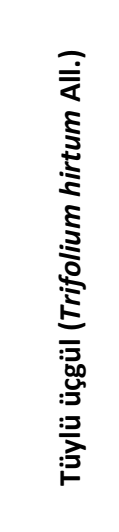 & 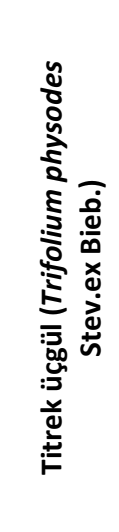 & 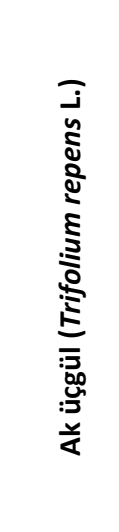 & 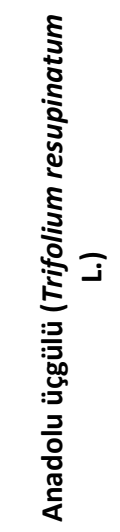 & 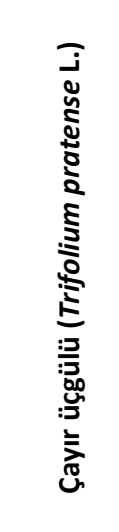 & 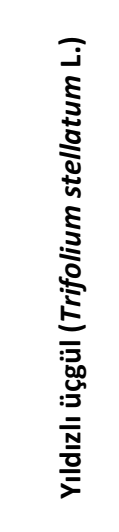 & 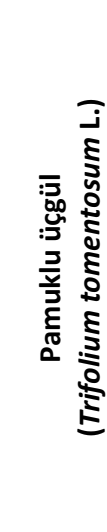 \\
\hline $\begin{array}{l}\text { Çiçeklenme } \\
\text { gün sayısı } \\
\text { (gün) } \\
\text { Fiz. olum }\end{array}$ & $130-155$ & $140-162$ & $123-142$ & $140-164$ & $124-135$ & $145-156$ & 175-190 & $162-172$ & $138-152$ & $144-162$ \\
\hline $\begin{array}{l}\text { gün sayısı } \\
\text { (gün) }\end{array}$ & $168-192$ & $184-205$ & $169-200$ & $174-198$ & $161-172$ & $178-201$ & $212-236$ & $199-224$ & 174-195 & $175-210$ \\
\hline Çiçek rengi & $\begin{array}{l}\text { Beyaz- } \\
\text { Pembe }\end{array}$ & Sarı & Beyaz & Pembe & Pembe & Beyaz & Lila & Lila & $\begin{array}{c}\text { Pembe- } \\
\text { Beyaz }\end{array}$ & Pembe \\
\hline $\begin{array}{l}\text { Bitki boyu } \\
(\mathrm{cm})\end{array}$ & $6-28$ & $13-32$ & $7-60$ & $12-25$ & $24-53$ & $18-31$ & $24-63$ & $45-70$ & $14-26$ & $11-22$ \\
\hline $\begin{array}{l}\text { Bin tane } \\
\text { ağırlığı (g) }\end{array}$ & 0.7-0.9 & $0.9-1.3$ & $0.8-1.3$ & $0.6-0.7$ & $1-1.2$ & $0.4-0.6$ & $0.9-1.4$ & $1-1.8$ & $0.5-0.7$ & $0.4-0.7$ \\
\hline $\begin{array}{l}\text { Meyvede } \\
\text { tane sayısı } \\
\text { (adet) }\end{array}$ & $1-2$ & $1-4$ & $1-3$ & $1-2$ & $1-3$ & $1-5$ & $1-4$ & $1-2$ & $1-2$ & $1-3$ \\
\hline $\begin{array}{l}\text { Kömeçte } \\
\text { çiçek sayısı } \\
\text { (adet) }\end{array}$ & $34-47$ & $42-51$ & $30-45$ & $48-62$ & $28-36$ & $44-82$ & $56-74$ & $65-72$ & $32-49$ & $40-52$ \\
\hline
\end{tabular}

\section{Kaynaklar}

Acar, Z., Ayan, i. ve Gülser, C. 2001. Some morphological and nutritional properties of legumes under natural conditions. Pakistan Journal of Biological Sciences, 4(11): 13121315.

Açıkgöz, E. 2001. Yem Bitkileri. Uludağ Üniversitesi Güçlendirme Vakfı Yayın No:182, Bursa.

Anonim, 2001. Tarımsal Değerleri Ölçme Denemeleri Teknik Talimatı (Baklagil Yem Bitkileri). Tarım ve Köyişleri Bakanlığı, Koruma ve Kontrol Genel Müdürlüğü, Tohumluk Tescil ve Sertifikasyon Merkezi Müdürlüğü, Ankara.

Anonim, 2008. Türkiye Çayır Mera Bitkileri Kılavuzu. Tarımsal Üretim ve Geliştirme Genel Müdürlüğü, T.C. Tarım ve Köyişleri Bakanlığı.
Başaran, U., Acar, Z., Mut, H. ve Aşcı, Ö.Ö. 2006. Doğal olarak yetişen bazı baklagil yem bitkilerinin bazı morfolojik ve tarımsal özellikleri. OMÜ Ziraat Fakültesi Dergisi. 21(3): 314-317.

Carlier, L. ve Machiels, M. 1998. Forages legumes: Possibilities for improvement of production. Proc. Latvian Academy of Sciences, 52: 300304.

Davis, P.H. 1982. Flora of Turkey and the East Aegean Islands. Vol. 7. Univ. Pres. Edinburgh.

Deveci, M. ve Şılbır, Y. 2005. Ordu ili ve çevresinde fındık bahçeleri altında bulunan doğal bitki türleri, hayat formları ve çiçeklenme periyotları. Türkiye VI. Tarla Bitkileri Kongresi, 5-9 Eylül 2005, Antalya. 
Deveci, M. 2012. An investigation on plant species diversity in colchic province. African Journal of Agricultural Research, 7(5): 820-843.

Ertuş, M.M. 2005. Ekim Zamanı ve Sıra Arası Mesafenin Acem Üçgülü (Trifolium resupinatum L.) Verim ve Diğer Bazı Özelliklerine Etkisi. Yüksek Lisans Tezi, Yüzüncü Yıl Üniversitesi, Fen Bilimleri Enstitüsü, Tarla Bitkileri Ana Bilim Dalı, Van.

Ertuş, M.M., Sabancı, C.O. ve Zorer Çelebi, Ş. 2012. Van ve çevresinde yetiştirilen yerel korunga (Onobrychis sativa) çeşitlerinin bazı özelliklerinin belirlenmesi. YYÜ Yıl Üniversitesi Tarım Bilimleri Dergisi, 22(3): 165-172.

Harlan, J.G. 1951. Anatomy of gene centers. American Naturalist, 85: 97-103.

Holt, E.C. ve Weaver, R.W. 1981. Performance and Management of Winter Legumes for Forage. PR-3876. Texas Agric. Exp. Stn., College Station.

Manga, İ., Acar, Z. ve Ayan, İ. 1995. Baklagil Yem Bitkileri. Ondokuz Mayıs Üniversitesi Yayınları, Samsun.

Muir, J.P., Pitman, W.D. ve Coombs, D.F. 2001. Seeding rate, phosphorus fertilization and location effects on "Armadillo" Burr Medic. Agronomy Journal, 93: 1269-1275.

Mut, H. 2009. Sürülüp terkedilen bir merada farklı ıslah yöntemlerinin etkinliklerinin belirlenmesi. Ondokuz Mayıs Üniversitesi Fen Bilimleri Enstitüsü Tarla Bitkileri Anabilim Dalı Doktora Tezi, Yayınlanmamış.

Namlı, O., Çolak. G., Opak. Y., Başaran, D. ve Yücel, S. 1994. Diyarbakır doğal koşullarında yetişen İran üçgülü (Trifolium resupinatum L.) üzerine ekolojik araştırmalar. Turkish Journal of Botany, 18: 57-63.

Özbucak, T.B., Kutbay, H.G. ve Özbucak, S. 2006. Ordu ili Boztepe piknik alanının florası. Ekoloji Dergisi, 15(59): 37-42.

Önal Aşcı, Ö., Deveci, M. ve Acar, Z. 2013. Bazı üçgül (Trifolium sp.) türlerinin besin değeri. Türkiye 10. Tarla Bitkileri Kongresi. Konya, 10-13 Eylül. Cilt III ss: 189-193.

Tekeli, A.S. ve Ateş, E. 2002. Adi fiğ (Vicia sativa L.) ve İran üçgülü (Trifolium resupinatum L.) hatlarında bazı verim öğelerinin varyasyonu ve kalıtımı. Trakya Ünivetsitesi Bilimsel Araştırmalar Dergisi, 3(1): 69-76. 